\title{
The place of peripheral neurectomy in the management of trigeminal neuralgia
}

\author{
A. J. FreEMont \\ B.Sc., M.R.C.P. \\ Paul Millac \\ M.D., F.R.C.P.
}

Neurology Department, Leicester Royal Infirmary, Leicester LE1 5WW

\begin{abstract}
Summary
One hundred and forty-six patients with trigeminal neuralgia were studied. Of 49 patients ultimately maintained pain-free by non-medical means, 26 underwent peripheral neurectomy. Twenty of these achieved excellent pain control in the longer term and 5 of the remaining 6 became more responsive to carbamazepine after operation. Seven patients required repeat neurectomies. Peripheral neurectomy is a useful and simple method of pain control in trigeminal neuralgia.
\end{abstract}

\section{Introduction}

Since its introduction in 1963, carbamazepine has become the treatment of choice in trigeminal neuralgia. However, experience shows $20-30 \%$ of patients require alternative treatment through failure of response or intolerance (Vinken and Bruyn, 1968). For them, a variety of procedures to modify or interrupt afferent impulses along the trigeminal pathway have been devised. These range from adjustment of the bite (Blair and Gordon, 1973) through division of the peripheral branches of the nerve to destruction of the Gasserian ganglion or surgical tractotomy. Excellent results have been obtained from injection of the trigeminal ganglion with alcohol (Penman, 1950) which, with radio-frequency diathermy of the nerve roots intracranially, constitutes the most widely practised management today. Necessarily, the expertise and equipment required for such techniques confines them to relatively few centres; moreover they may cause a distressing degree of sensory loss. For these reasons, less extensive peripheral neurectomies have been utilized over the years. Some have summarily dismissed these by virtue of their impermanence (Loesser, 1977), others have advanced them as simple and successful techniques (Quinn, 1965; Grantham and Segerberg, 1952). Few reports of the long-term outcome have been published and the authors have therefore reviewed their own experience.

\section{Materials and methods}

Records of all patients attending the departments of neurology and oral surgery at the Leicester Royal
Infirmary between 1963 and 1978 were studied. There were 148 case notes available, and 146 patients fulfilled the diagnostic criteria of paroxysmal facial pain restricted to the divisions of the trigeminal nerve, sudden in onset and with abrupt termination, triggered by non-nociceptive stimuli. There were 56 men and 90 women with a mean age of 63 years at presentation. The first division was involved in 5 patients, the second in 61 and the third in 70 . In 10 patients, 2 divisions (all 2nd and 3rd) were implicated. Patients who failed to respond to medical treatment underwent alcohol ganglionolysis performed by Dr John Penman at Atkinson Morley's Hospital, London, or by the neurosurgical unit at the Derbyshire Royal Infirmary where the surgical tractotomies were also carried out. Peripheral neurectomy or peripheral alcohol neurolysis was performed by the Department of Oral Surgery at the Leicester Royal Infirmary. Peripheral neurectomy involved exposing the appropriate nerve under local anaesthesia, placing it under tension and excising a proximal segment. The foramen was then packed with fatty tissue. Follow-up in all cases was obtained from a combination of case notes, questionnaires sent to patients and information from general practitioners.

\section{Results}

Of the 146 patients studied, 135 commenced on carbamazepine. Eleven patients seen initially in the Department of Oral Surgery were managed with adjustment of bite or with surgical measures as primary treatment. At the end of the study 97 patients $(67 \%)$ given carbamazepine remained painfree. Forty-nine patients $(28 \%)$ underwent surgical procedures, 38 of them for failed medical treatment. By the end of the study period, 20 patients were pain-free following peripheral neurectomy, 2 after alcohol neurolysis, 14 after ganglionolysis, 4 after dental manipulations, 4 after rhizotomy and one after radio-frequency diathermy. During the study, a few patients underwent more than one form of treatment and a few one type of treatment more than once. The patients pain-free at completion on carbamazepine were mostly taking $600-800 \mathrm{mg}$ daily. 
The effectiveness of the various procedures used was assessed by the proportion of patients who were pain-free after set periods. Patients who died painfree before an assessment interval were excluded from that particular cohort.

Twenty-six patients had peripheral neurectomies of whom 20 remained pain-free until death or the end of the study. Two required simultaneous neurectomies of 2 branches, one of both infraorbital and inferior dental nerves and the other lingual and dental nerves. Seven patients required repeat neurectomies; regeneration of the nerve had occurred in every instance. Three patients underwent 2 neurectomies; one patient, $3 ; 2$ patients, 4 ; and one patient, 5 . Serial neurectomies gave on average a 59-month pain-free period, all patients being pain-free or having died pain-free on completion of the study period.

In 6 patients, neurectomy proved inadequate. Five were subsequently controlled with carbamazepine which had proved ineffective in larger doses previously.

The table compares the results of different treatment in the patients. There was no mortality from any procedure in this study, anaesthesia dolorosa was encountered in one patient after ganglion injection. Six patients required tarsorrhaphies amongst the 21 who had ganglion injection or rhizotomy. Neither anaesthesia dolorosa nor corneal anaesthesia was encountered in peripheral procedures.

\section{Discussion}

Peripheral neurectomy has been criticized for its lack of permanence but the authors' experience shows that following serial neurectomies patients may still be pain-free after 6 years. A single neurectomy yields, on average, 26.5 months free of pain.

TABLE 1. Pain free interval following surgical treatment of trigeminal neuralgia

\begin{tabular}{lccc}
\hline \multicolumn{1}{c}{ Treatment } & $\begin{array}{c}\text { Peripheral } \\
\text { neurectomy }\end{array}$ & $\begin{array}{c}\text { Alcohol } \\
\text { neuronolysis }\end{array}$ & $\begin{array}{c}\text { Intracranial } \\
\text { procedures }\end{array}$ \\
\hline $\begin{array}{l}\text { No. of patients } \\
\text { No. of procedures }\end{array}$ & 26 & 7 & 21 \\
$\begin{array}{l}\text { Average period } \\
\text { of relief }\end{array}$ & 43 & 13 & 29 \\
Pain relief & $23 / 12$ & $15 / 12$ & $93 / 12$ \\
$\quad$ immediate $\%$ & 97 & 100 & 83 \\
1 year & 82 & 62 & 69 \\
2 years & 48 & 23 & 69 \\
3 years & 28 & 0 & 65 \\
5 years & 17 & 0 & 62 \\
6 years & 4 & 0 & 55 \\
10 years & 0 & 0 & 55 \\
13 years & 0 & 0 & 55 \\
\hline
\end{tabular}

This compares with other series (Quinn, 1965; Grantham and Segerberg, 1952). Even those whose $\stackrel{\varnothing}{\propto}$ pain was not completely controlled by peripheral $c$. neurectomy proved more responsive to carba- $\overrightarrow{\vec{F}}$ mazepine subsequently.

Patients who underwent both alcohol neurolysis and peripheral neurectomy found the former painful and preferred the latter which gave more sure and durable pain relief.

The more radical procedures have significant dis- \& advantages. Facial anaesthesia is more extensive $\vec{\circ}$ than in peripheral procedures and corneal anaesthesia is an important complication encountered in $\vec{\omega}$ $31-82 \%$ of ganglionolyses (Penman, 1950; Henderson, 1967), $75 \%$ of those who have intracranial surgery and $6 \%$ of radio-frequency diathermies 3 . (Loesser, 1977). Anaesthesia dolorosa afflicted one $v$ of the present patients after ganglionolysis and is a regular, if infrequent, complication of procedures $\$$ producing more extensive anaesthesia which has or not been reported after peripheral neurectomy. 을 Finally, there is the greater cost and inconvenience in transferring patients to distant centres for treatment.

The authors' experience over 15 years leads them to take issue with those who declare peripheral neurectomy to be unsafe and accord it no place the management of trigeminal neuralgia. It is sug $\overrightarrow{0}$ gested that there is every reason to consider th $\infty$ method of management in the patient who, by virtue of age, frailty or coincidental disease, has $\vec{a}$ restricted life expectancy; in those patients who express reservations over the anaesthesia which would result from root or ganglion destruction; where the diagnosis is uncertain and where there is delay in access to special centres for a more major procedure. Whilst it may be used as a primary therapeutic measure the authors feel it is better reserved for those patients in whom medical therapy fails or is poorly tolerated.

\section{References}

BlaIR, G.A.S. \& GoRdon, D.S. (1973) Trigeminal neuralgia and dental malocclusions. British Medical Journal, 4, 38.

Grantham, E. \& Segerberg, L.H. (1952) An evaluation of palliative surgical procedures in trigeminal neuralgia, Journal of Neurosurgery, 9, 390.

Henderson, W.R. (1967) Trigeminal neuralgia: The pain and its treatment. British Medical Journal, 1, 7.

LOESSER, J.D. (1977) The management of tic douloureux. Pain, 3, 155.

Penman, J. (1950) The differential diagnosis and treatment of tic douloureux. Postgraduate Medical Journal, 26, 627.

QuINN, J.H. (1965) Repetitive peripheral neurectomies for neuralgia of 2 nd and 3 rd divisions of the trigeminal nerve. Journal of Oral Surgery, 23, 600.

Vinken, P.J. \& BRUYN, G.W. (1968) Handbook of Clinical Neurology, p. 383. North Holland Publishing Company, New York. 